\title{
A study of cervical cytology in females above 21 years of age
}

\author{
Nidhi Singh*, Hanslata Gehlot
}

Department of Obstetrics and Gynecology, Dr. S. N. Medical College, Jodhpur, Rajasthan, India

Received: 12 May 2019

Revised: 12 July 2019

Accepted: 14 August 2019

*Correspondence:

Dr. Nidhi Singh,

E-mail: dr.nidhisingh20@gmail.com

Copyright: ( ) the author(s), publisher and licensee Medip Academy. This is an open-access article distributed under the terms of the Creative Commons Attribution Non-Commercial License, which permits unrestricted non-commercial use, distribution, and reproduction in any medium, provided the original work is properly cited.

\begin{abstract}
Background: Cancer cervix is the leading cause of mortality and morbidity in developing countries like India most probably due to lack of proper screening facilities or due to the lack of awareness amongst the women of developing countries. Worldwide, cervical cancer is the second most common and 5th deadliest cancer in women. This study was conducted in department of obstetrics and Gynaecology, Umaid hospital, Dr. S. N. Medical College, Jodhpur Rajasthan, India. The objective of this study was to study the various high risk factors involved in premalignant and malignant lesions of cervix. To study the incidence of different epithelial abnormalities of cervix in females above 21 years of age. To study premalignant and malignant lesions of the cervix in relation to the presenting complaint

Methods: The study was conducted in 500 females above 21 years of age and who were not pregnant, who had been attending Umaid Hospital, Jodhpur for various gynaecological complaints, of different parity, residential status and socioeconomic class. Detailed history was taken and thorough examination was done. Pap smear was prepared and all smears were reported as per the Bethesda system.

Results: Maximum numbers of patients were in the age group of 21-40 years (70.2\%). Majority of patients were from rural area (52.4\%) and from lower socioeconomic class (30.2\%). Most of women were found to have duration of marriage between 10 to 30 years $(63.4 \%)$. Most of the women in our study had age at marriage between 17 to 19 years $(49.4 \%)$. Multiparity was seen in $84.2 \%$ of cases. The commonest presenting complaint was white discharge (46.8\%). On Pap smear, maximum cases were of inflammatory smear (91.4\%), 1.4\% had ASCUS, $1.2 \%$ AGC, $1.4 \%$ LSIL, $1 \%$ HSIL and $0.4 \%$ had SCC.

Conclusions: Cervical cytology is an important tool for early detection of premalignant and malignant lesions of cervix. Regular pap smear screening should be conducted in vulnerable age groups.
\end{abstract}

Keywords: Cervical cancer, Cervical intraepithelial neoplasia, Pap smear, The bethesda system

\section{INTRODUCTION}

Cervical cancer is an important health problem and leading cause of morbidity and mortality amongst women globally. Worldwide, it is the second- most common and 5 th deadliest cancer in women but in India, cervical cancer is the most common genital cancer encountered in clinical practice. ${ }^{1}$ Every year in India, 1,22,844 women are diagnosed with cervical cancer and 67,477 die from the disease. ${ }^{2}$ Cervical cancer is the second most common cancer in women aged 15-44 years. India has the highest age standardized incidence of cervical cancer in South Asia at 22 per 100,000 woman per year, compared to 19.2 in Bangladesh, 13 in Sri Lanka and 2.8 in Iran. ${ }^{2}$ The 5 year survival rate of cervical cancer when detected at the earliest stage is $92 \%$. It is a preventable disease which if detected early can reduce the morbidity and mortality associated with cervical cancer. About $80-85 \%$ of cases 
are detected in stage $\mathrm{III} / \mathrm{IV}^{3,4} \mathrm{~A}$ regular screening programme is capable of reducing the incidence of invasive cervical cancer.

Since early detection predicts better prognosis, one of the most effective ways of preventing and controlling cervical cancer is regular screening and early diagnosis. The most effective method of screening employed in the developed world has been cytology based using Pap smears, which has contributed considerably to reducing incidence of and mortality from cervical cancer.

Cervical cancer is the second most commonly diagnosed cancer in women. Worldwide, it is estimated that there are approximately half million new cases of cervical cancer each year, accounting for approximately $12 \%$ of all female cancers. Cytology is most effective and practical method for cervical cancer screening, as it is simple, relatively inexpensive, reliable, less time consuming and generally applicable.

Hence a method which is simple and inexpensive is more likely to be successful as a screening procedure. The use of papanicolaou technique of screening for cervical cancer and appropriate interventions is a simple, wellrecognized and appreciated method of early diagnosis and should in theory be capable of completely abolishing the incidence of invasive cervical cancer in a completely screened population. It is important to define the highrisk population for the screening of cervical neoplasia, dysplasia and other inflammatory lesions.

To study the various high risk factors involved in premalignant and malignant lesions of cervix. To study the incidence of different epithelial abnormalities of cervix in females above 21 years of age. To study premalignant and malignant lesions of the cervix in relation to the presenting complaint.

\section{METHODS}

This is an observational study, carried out in the department of obstetrics and gynaecology, Umaid hospital, attached to Dr. S.N. Medical College, Jodhpur.
The study has been conducted from January 2017 to June 2017, included 500 females above 21 years of age, who were not pregnant and who had been attending Umaid Hospital, for various gynaecological complaints, of different parity and residential status. Detailed history was taken and thorough examination was done. Pap smear were prepared and all smears were reported as per the Bethesda system. ${ }^{5}$

Pap smears were obtained from squamocolumnar junction with the help of Ayre's spatula. The material obtained was quickly smeared on a clean glass slide and the smear was immediately fixed in $95 \%$ ethyl alcohol. In the central laboratory, the slides were stained with Papanicolaou stain and examined under light microscope. The cytological interpretation of the smears was made according to The Bethesda System 2014 (TBS).

The test was invented by, and named for, the prominent Greek doctor George Papanicolaou.The test aims to detect potentially precancerous changes, called cervical intraepithelial neoplasia (CIN) or cervical dysplasia; squamous intraepithelial lesion system ( SIL) is also used to describe abnormalities, which are caused by HPV, a sexually transmitted DNA virus. The test remains an effective, widely used method for early detection of precancer and cervical cancer. While the test may also detect infections and abnormalities in the endocervix.

\section{RESULTS}

The study comprised of 500 patients above 21 years of age group who were attending Umaid Hospital, Gynaecology Department for various Gynecological Complaints. Cervical Smear was taken from all these cases.

According to Table 1, maximum number of patients was in the age group of 30-40 years i.e. $36.4 \%$. The number of cases between 20-30 years were $33.8 \%$, 40-50 years were $21.2 \%, 50-60$ years were $5 \%$, between $60-70$ years were $3.2 \%$ and least number of cases were in the age group of more than 70 years i.e. $0.4 \%$, of total of the 500 cases in our study.

Table 1: Distribution of cases according to age.

\begin{tabular}{|lllll|}
\hline Age group & No. of cases & Percentage & Abnormal cytology & Percentage \\
\hline $21-30$ years & 169 & $33.8 \%$ & 01 & $0.2 \%$ \\
\hline $30-40$ years & 182 & $36.4 \%$ & 12 & $2.4 \%$ \\
\hline $40-50$ years & 106 & $21.2 \%$ & 06 & $1.2 \%$ \\
\hline $50-60$ years & 25 & $5 \%$ & 01 & $0.2 \%$ \\
\hline $60-70$ years & 16 & $3.2 \%$ & 06 & $1.2 \%$ \\
\hline$>70$ years & 2 & $0.4 \%$ & 01 & $0.2 \%$ \\
\hline Total & $\mathbf{5 0 0}$ & & $\mathbf{2 7}$ & $\mathbf{5 . 4 \%}$ \\
\hline
\end{tabular}


According to Table 2, majority of cases i.e. $52.4 \%$ were from the rural population.
As shown in Table 3, majority of the patients were in the lower socioeconomic class $(30.2 \%)$ and lower middle class $(26.2 \%)$.

Table 2: Distribution of cases according to residential area.

\begin{tabular}{|lllll|}
\hline Residential area & No. of cases & Percentage & Abnormal cytology & Percentage \\
\hline Rural & 262 & $52.4 \%$ & 19 & $3.8 \%$ \\
\hline Urban & 238 & $47.6 \%$ & 08 & $1.6 \%$ \\
\hline Total & $\mathbf{5 0 0}$ & & $\mathbf{2 7}$ & $\mathbf{5 . 4 \%}$ \\
\hline
\end{tabular}

Table 3: Distribution according to socioeconomic status (according to modified B.G.Prasad Scale 2017).

\begin{tabular}{|lllll|}
\hline Socioeconomic status & No. of cases & Percentage & Abnormal cytology & Percentage \\
\hline Upper class (I) & 52 & $10.4 \%$ & 0 & 0 \\
\hline Upper middle class (II) & 53 & $10.6 \%$ & 01 & $0.2 \%$ \\
\hline Middle class (III) & 113 & $22.6 \%$ & 07 & $1.4 \%$ \\
\hline Lower middle class (IV) & 131 & $26.2 \%$ & 09 & $1.8 \%$ \\
\hline Lower class (V) & 151 & $30.2 \%$ & 10 & $2 \%$ \\
\hline Total & $\mathbf{5 0 0}$ & & $\mathbf{2 7}$ & $\mathbf{5 . 4 \%}$ \\
\hline
\end{tabular}

Table 4: Distribution according to duration of married life in years.

\begin{tabular}{|lllll|}
\hline Duration of married life in years & No. of cases & Percentage & Abnormal cytology & Percentage \\
\hline 1 to 10 & 129 & $25.8 \%$ & 03 & $0.6 \%$ \\
\hline 10 to 20 & $\mathbf{1 8 4}$ & $\mathbf{3 6 . 8 \%}$ & $\mathbf{0 8}$ & $\mathbf{1 . 6 \%}$ \\
\hline 20 to 30 & 133 & $26.6 \%$ & 07 & $1.4 \%$ \\
\hline 30 to 40 & 36 & $7.2 \%$ & 02 & $0.4 \%$ \\
\hline 40 to 50 & 13 & $2.6 \%$ & 03 & $0.6 \%$ \\
\hline$>50$ & 5 & $1 \%$ & 04 & $0.8 \%$ \\
\hline Total & $\mathbf{5 0 0}$ & & $\mathbf{2 7}$ & $\mathbf{5 . 4 \%}$ \\
\hline
\end{tabular}

Table 5: Distribution according to age at marriage.

\begin{tabular}{|lllll|}
\hline Age at marriage & No. of cases & Percentage & Abnormal cytology & Percentage \\
\hline $14-16$ & 25 & $5 \%$ & 0 & 0 \\
\hline $17-19$ & 247 & $49.4 \%$ & 20 & $4 \%$ \\
\hline $20-24$ & 203 & $40.6 \%$ & 07 & $1.4 \%$ \\
\hline $25-29$ & 25 & $5 \%$ & 0 & 0 \\
\hline Total & $\mathbf{5 0 0}$ & & $\mathbf{2 7}$ & $\mathbf{5 . 4 \%}$ \\
\hline
\end{tabular}

Table 6: Distribution of cases according to parity.

\begin{tabular}{|lllll|}
\hline Parity & No. of cases & Percentage & Abnormal cytology & Percentage \\
\hline Nulliparous & 33 & $6.6 \%$ & 0 & 0 \\
\hline 1 & 46 & $9.2 \%$ & 02 & $0.4 \%$ \\
\hline 2 to 5 & 402 & $80.4 \%$ & 21 & $4.2 \%$ \\
\hline$>5$ & 19 & $3.8 \%$ & 04 & $0.8 \%$ \\
\hline Total & $\mathbf{5 0 0}$ & & $\mathbf{2 7}$ & $\mathbf{5 . 4 \%}$ \\
\hline
\end{tabular}

As shown in Table 4, most of women were found to have duration of marriage between 10 to 20 years i.e. $36.8 \%$ women, $26.6 \%$ women had marriage duration of 20 to 30 years, $25.8 \%$ women had marriage duration of 1 to 10 years, $7.2 \%$ women had married life of 30 to 40 years, $2.6 \%$ women had marriage duration of 40 to 50 years and only $1 \%$ women had married life of $>50$ years. 
According to Table 5, most of the women in our study group had age at marriage between 17 to 19 years i.e. $49.4 \%$.
As depicted in the Table 6, majority of patients i.e. $84.2 \%$ patients were multipara and only $6.6 \%$ were nullipara.

Table 7: Distribution according to symptoms.

\begin{tabular}{|lllll|}
\hline Symptom & No. of cases & Percentage & Abnormal cytology & Percentage \\
\hline Vaginal discharge & 234 & $46.8 \%$ & 10 & $2 \%$ \\
\hline Pain in lower abdomen & 187 & $37.4 \%$ & 08 & $1.6 \%$ \\
\hline Itching vulva & 130 & $26 \%$ & 07 & $1.4 \%$ \\
\hline Urinary complaint (burning micturition) & 59 & $11.8 \%$ & 01 & $0.2 \%$ \\
\hline Irregular bleeding & 35 & $7 \%$ & 09 & $1.8 \%$ \\
\hline Postcoital bleeding & 13 & $2.6 \%$ & 04 & $0.8 \%$ \\
\hline Post menopausal bleeding & 9 & $1.8 \%$ & 06 & $1.2 \%$ \\
\hline
\end{tabular}

As depicted in the Table 7, the commonest complaint was vaginal discharge $(46.8 \%)$ followed by pain in lower abdomen (37.4\%) and itching vulva (26\%) and least common complaints were irregular menses (7\%), postcoital bleeding $(2.6 \%)$ and post menopausal bleeding $(1.8 \%)$.

Table 8: Study group according to Pap smear finding.

\begin{tabular}{|lll|}
\hline Cytology report & No. of cases & Percentage \\
\hline $\begin{array}{l}\text { Negative for } \\
\text { intraepithelial lesion }\end{array}$ & 473 & $94.6 \%$ \\
\hline $\begin{array}{l}\text { Non- specific } \\
\text { inflammatory smears }\end{array}$ & 457 & $91.4 \%$ \\
\hline Bacterial vaginosis & 16 & $3.2 \%$ \\
\hline ASCUS & 07 & $1.4 \%$ \\
\hline AGC & 06 & $1.2 \%$ \\
\hline LSIL & 07 & $1.4 \%$ \\
\hline HSIL & 05 & $1 \%$ \\
\hline SCC & 02 & $0.4 \%$ \\
\hline Total & $\mathbf{5 0 0}$ & \\
\hline
\end{tabular}

As depicted in the Table 8, most common finding was NILM $(94.6 \%)$, the incidence of dysplasia in our study is $5 \%$ ( 25 cases) and the incidence of malignancy is $0.4 \%$ (2 cases).

\section{DISCUSSION}

A regular screening programme is capable of early detection of cervical cancer in a community at the stage of dysplasia and thus reducing the morbidity and mortality.

Cytology is most effective and practical method for cervical cancer screening, as it is simple, relatively inexpensive, reliable, less time consuming and easily applicable.

In our present study, evaluation of cervical smear in women above 21 years of age attending Umaid Hospital, Jodhpur with various gynaecological complaints was done, in order to study the various high risk factors involved in the premalignant and malignant lesions of the cervix and patients were evaluated on the basis of their age, residential status, duration of marriage, age at marriage, parity, presenting complaint. A cervical smear was prepared from all these 500 cases and the slides were studied and interpreted by pathologist.

Most of the women were in the age group of 31 to 40 years i.e. $36.4 \%$ and 21 to 30 years i.e. $33.8 \%$. Similar results are found in studies conducted by Rajput et al, Vaghela et al, Bamanikar et al, Umarani et al, Bhavani K et al. ${ }^{6-10}$ This age group is most vulnerable for manifestations of cervical pathology as cervical lesions are slowly growing and takes 10-12 years to manifest after cervical insult.

In our observation, $52.4 \%$ cases were from rural population and $47.6 \%$ of cases from urban population. The incidence of cervical cancer was found to be the highest in the females belonging to rural areas. Our findings are consistent with the studies conducted by Rajput et al, Roopali et al, Maibam et al. ${ }^{6,11,12}$ Since over $70 \%$ of the Indian population resides in the rural areas, so the incidence is higher in rural population. There is high incidence of cervical cancer among rural females due to lack of personal hygiene, low nutritional status, low literacy rate, repeated births and lack of access to health services in rural setup. All these are the risk factors for cervical dysplasias and hence cervical cancer.

Majority of patients were in the lower socioeconomic class (30.2\%), which was comparable to studies conducted by Kaur et al $(42.1 \%)$ and Verma et al $(32 \%){ }^{13,14}$ In the present study, low socioeconomic level is a significant risk factor. The relationship of cervical cancer with low socioeconomic status is closely associated with cervical screening attendance and unhealthy lifestyle. Income plays a great role in influencing access to proper early detection and treatment of precancerous conditions. Economic constraints prioritize women towards financial and social responsibilities and self neglect towards their health 
issues by curtailing their expenses in the form of time and money in visiting health centres.

Duration of marriage and duration of exposure to sexual intercourse had a distinct role in genesis of cervical dysplasia. Majority of women $(74.2 \%)$ had duration of married life of $>10$ years. Similar findings have been published by other studies conducted by Khalaf MK et al (70.5\%), Zainab et al $(51.92 \%)$, Tapasvi I et al (92.3\%). ${ }^{15-17}$ Early marriages, leads to longer sexual life and being sexually active for longer duration elevates the number of pregnancies, abortions, deliveries and increases the chances of sexually transmitted infection. HPV is a very common sexually transmitted infection worldwide and its infection has been found in almost all cases of invasive cervical cancer. The time from infection to the development of invasive cancer is thought to be many years; typically between 10 and 40 .

Maximum number of patients had age at marriage between $17-19$ years i.e. $49.4 \%$, and between $20-24$ years in $40.6 \%$ cases. The present findings were in accordance with the observations made by Rajput et al, Roopali et al, Kaur et al, Khalaf et al, Bhalero et al, Gupta $\mathrm{K}$ et al. $6,11,13,15,18,19$ Marriage at younger age then leads to longer sexual life which proves to be a significant risk factor in cervical dysplasia and also increases susceptibility of adolescent cervix to oncogenic irritation. The adolescent cervix is vulnerable to various potential oncogenic factors (HPV) when exposed and results in increase incidence of dysplasia and its further course.

Majority of patients were multipara (80.4\%), which was comparable to other studies by Rajput et al, Verma et al, Zainab et al, Bhalero et al, Schiff et al. ${ }^{6,14,16,18,20}$ High parity has been associated with cervical neoplasia even after adjustment for sexual activity and other risk factors. Possible mechanisms that have been hypothesized include hormonal effects on cervical epithelium, prolonged immunosuppressant during multiple pregnancies. Pregnancy may produce some dysplastic lesions of the cervix which regress, persist or progress to carcinoma. Trauma to the cervix is one of the possible explanations that warrant explorations include increased susceptibility to infection through immunosuppressant, hormonal influence and dietary deficiencies.

Commonest presenting complaint was white discharge per vagina found in $46.8 \%$ patients which is comparable to the studies conducted by Rajput et al (73.5\%), Bamanikar et al (51.8\%), Bhalero et al (71\%), Papa dasari et al (44.7\%), Ashok Verma et al (54.5\%). ${ }^{6,8,18,21,22}$

Present study shows the pap smear findings of women. In our study, $94.6 \%$ were having negative for intraepithelial lesion or malignancy on pap smear, which corresponds to the following studies conducted by Vaghela et al $(70.75 \%)$, Bamanikar et al $(88.93 \%)$, Umarani et al $(82.08 \%)$, Bhavani $\mathrm{K}$ et al $(90.77 \%) .^{7-10}$
1.4\% ASCUS, which corresponds to the studies conducted by Vaghela et al (2.8\%), Bamanikar et al (2.32\%), Umarani et al (5.34\%), Bhavani K et al $(2.33 \%)$, Verma A et al (1\%). ${ }^{7-10,22}$ A higher incidence of ASCUS was found in study by Umarani et al $(5.34 \%)$ due to the more number of cases and long duration of studies.

$1.2 \%$ AGC, which corresponds to the studies by Vaghela et al $(1.4 \%)$ and Umarani et al $(0.64 \%){ }^{7,9}$

$1.4 \%$ of cases had LSIL, which is comparable to the studies Bamanikar et al (1.96\%) and Umarani et al $(1.62 \%){ }^{8,9}$

$1 \%$ had HSIL, which is comparable to studies by Umarani et al $(0.64 \%)$ and Bhavani $\mathrm{K}$ et al (1.8\%). ${ }^{9,10}$

$0.4 \%$ had SCC, which corresponds to the results by Bamanikar et al (0.53\%), Umarani et al (0.28\%), Bhavani $\mathrm{K}$ et al $(0.12 \%){ }^{8-10}$

\section{CONCLUSION}

For over five decades, the national standard for cervical cancer screening has been the Papanicolaou test, which is largely responsible for the dramatic $90 \%$ decrease in mortality and $70 \%$ decrease in cervical cancer. Cytology has been the mainstay for cervical cancer screening for decades and has led to a substantial reduction in cervical cancer incidence in countries with screening programs. The cytological method of diagnosis is convenient, valuable, technically sound and feasible method for detection of unsuspected carcinoma of genital tract and precancerous lesions at the time when they are not evident clinically. Various epidemiological factors play an important role in pathogenesis of disease. So favourable modifications can play an important role in decreasing morbidity and mortality associated with disease. So, it is important to identify and screen the high-risk population and social reforms motivate the optimal education of women for development of a positive attitude towards cancer consciousness and to make screening programme successful.

Funding: No funding sources

Conflict of interest: None declared

Ethical approval: The study was approved by the Institutional Ethics Committee

\section{REFERENCES}

1. Malur PR, Desai BR, Dalal A, Dundi G, Sherigan B, Gupta P. A study on sequential screening with cytology and colposcopy in detection of cervical Neoplasia. South Asian Federation of Obstet Gynaecol. 2009;1(3):45-8.

2. ICO information centre on HPV and cancer. Human Papillomavirus and related diseases in India. Summary Report. 2014:2014. 
3. Anderson SG, Linton EB. The diagnostic accuracy of cervical biopsy and cervical conisation. Am J Obstet Gynaecol. 1967;99:113.

4. Camsor and Gall. Dysplasia and early neoplasia of uterine cervix: a review. Obstet Gynaec Survey. 1974;34:1.

5. Rosa M. Cervix- Cytology. Bethesda System 2001 for cervicovaginal cytology reporting. 2010.

6. Rajput N, Verma YS, Ahirwar G. Detection of abnormal cervical cytology by pap's smear and comparison between rural and urban women. J Evolut Med Dent Sci. 2013;2(41):4923-30.

7. Vaghela BK, Vaghela VK, Santwani PM. Analysis of abnormal cervical cytology in papanicolaou smear at tertiary care centre: a retrospective study. Int J Biomed Adv Res. 2014;5(1);47-49.

8. Bamanikar SA, Baravkar DS, Chandanwale SS, Dapkekar P. Study of cervical pap smears in a tertiary Hospital. Indian Medical Gazette. 2014;250254.

9. Umarani MK, Gayathri MN, Madhu Kumar R. Study of cervical cytology in papanicolaou smears in a tertiary care hospital. Indian J Pathol Oncol. 2016;3(4):679-83.

10. Bhavani K, Sheela PV, Vani I, Jyothsna Y, Uma N. Study of cervical cytology in papanicolaou smears in a tertiary care center. IAIM. 2017;4(11):172-6.

11. Roopali. Sociodemographic risk factors for cervical cancer in Jammu and Kashmir state of India first ever report from Jammu. Indian $\mathbf{J}$ Sci Res. 2014;9(1):105-10.

12. Maibam AD, Singh KI. International Scholarly and Scientific Research Innovation. 2017;11(8):2076-9.

13. Kaur T, Garg S, Mor S. Sociodemographic and reproductive risk factors in cervical cancer. Int $\mathrm{J}$ Reprod Contracept Obstet Gynecol. 2016 May;5(5):1510-3.

14. Khushboo V. Clinical assessment and correlation of pap smear and liquid based cytology in bad cervix. J Evolut Med Dent Sci. 2014;53(16):12277-87.
15. Khalaf MK, Rasheed FA, Hussain SAR. Association between early marriage and other sociomedical characterstics with the cervical pap smear results in Iraqi Women. Adv Sexual Med. 2015;5:73-82.

16. Nayani ZS, Hendre PC. Comparison and correlation of pap smear with colposcopy and histopathology in evaluation of cervix. J Evol Med Dent Sci. 2015;4(53):9236-47.

17. Tapasvi I, Tapasvi C, Aggarwal A. To correlate the effect of parity, age of marriage, religion, socioeconomic status and contraception practiced in the development of premalignant and malignant lesions of cervix. Int $\mathbf{J}$ Res Health Sci. 2015;3(1):174-8.

18. Bhalero A. Correlative study of pap smear, colposcopy and histopathology. J South Asian Federat Obstet Gynaecol. 2012;4(2):97-8.

19. Gupta K. Prevalence of cervical dysplasia in western Uttar Pradesh. Department of Pathology, Lala Lajpat Rai Memorial Medical College, Meerut, Uttar Pradesh, India. J Cytol. 2013;30(4):257-62.

20. Schiff M, Miller J, Masuk M. Contraceptive and reproductive risk factors for cervical intraepithelial neoplasia in American Indian Women, Medicine and health. Int J Epidemiol. 2000:29(6):983-90.

21. Dasari P, Rajathi S, Kumar SV. Colposcopic evaluation of cervix with persistent inflammatory pap smear: a prospective analytical study. Cyto J. 2010;7:16.

22. Verma A, Verma S, Vashist S, Attri S, Singhal A. A study on cervical cancer screening in symptomatic women. Middle East Ferti Soc J. 2017;22(1):39-42.

Cite this article as: Singh N, Gehlot H. A study of cervical cytology in females above 21 years of age. Int J Reprod Contracept Obstet Gynecol 2019;8:3578-83. 